\title{
Codes for solar flux calculation dedicated to central receiver system applications: A comparative review
}

\author{
Pierre Garcia $^{\mathrm{a}, *}$, Alain Ferriere ${ }^{\mathrm{a}}$, Jean-Jacques Bezian ${ }^{\mathrm{b}}$ \\ a CNRS-PROMES Laboratory, 7 rue du four solaire, 66120 Font-Romeu, France \\ ${ }^{\mathrm{b}}$ CNRS-LGPSD Laboratory, Campus Jarlard, 81013 Albi Cedex 9, France
}

\begin{abstract}
As we need adapted software to calculate the solar flux concentration through a tower-heliostat field system, an overview of computer codes was performed, detailing their features, strengths and weaknesses. For this a questionnaire was sent to developers or heavy users of codes that are currently used in the concentrated solar power (CSP) community. Answers to this questionnaire make it possible to determine which tool is relevant depending on the objectives of the simulation. Modeling tools for central receiver systems (CRS) can be divided into two main categories, corresponding to two kinds of problems: on one hand those dedicated to system optimization and on the other hand those designed to detailed analysis of the optical performances. A bibliographic study on first generation and developing codes complements this overview of tools that may be interesting for CSP research or industry.
\end{abstract}

Keywords: Solar flux calculation; Central receiver systems; Optical modeling; Ray-tracing; Cone optics

\section{Introduction}

To optimize and design a CRS it is essential to know the performances of the subsystem formed by the tower and the heliostat field. Experimental work in this field has shown the necessity to master user-friendly modeling tools to design, simulate and optimize solar components of tower plants. Unluckily a lot of work is generally needed to adapt the codes for concentrated solar flux calculation to specific features and specific needs of each project. None of such codes can be considered as a standard tool for research or industry applications. Our purpose is not to develop another tool - many of them are available and effective - but to screen existing codes, trying to determine which one should be used depending on the objectives of the simulation, and which results can be expected. Such

\footnotetext{
* Corresponding author. Tel.: +33 468307 714; fax: +33 468302940 . E-mail address: pierre.garcia@promes.cnrs.fr (P. Garcia).
}

comparison had already been initiated in the frame of SolarPACES (solar power and chemical energy systems, IEA implementing agreement) to validate optical tools on a standard test case (Pitz-Paal and Schwarzbözl, 2000), but to our knowledge this work was not continued.

Concerning heliostat fields, two kinds of problems can be distinguished. The first one is an optimization problem: "What is the best heliostat field layout to maximize the collected solar energy or to minimize the cost of that energy?"; the second one is a performance calculation: "What is the power reflected by the field and arriving on the receiver aperture?" The PROMES laboratory is interested in both problems. Indeed, one goal is to be able to optimize the design of any CRS project at any location on economic criteria such as cost of the produced electricity. An additional goal is to assess the performances of the solar field for the PEGASE (Garcia et al., 2006) project located at THEMIS (Targasonne, France, see Fig. 1). To answer this double objective, the needed tool must be able to determine flux 

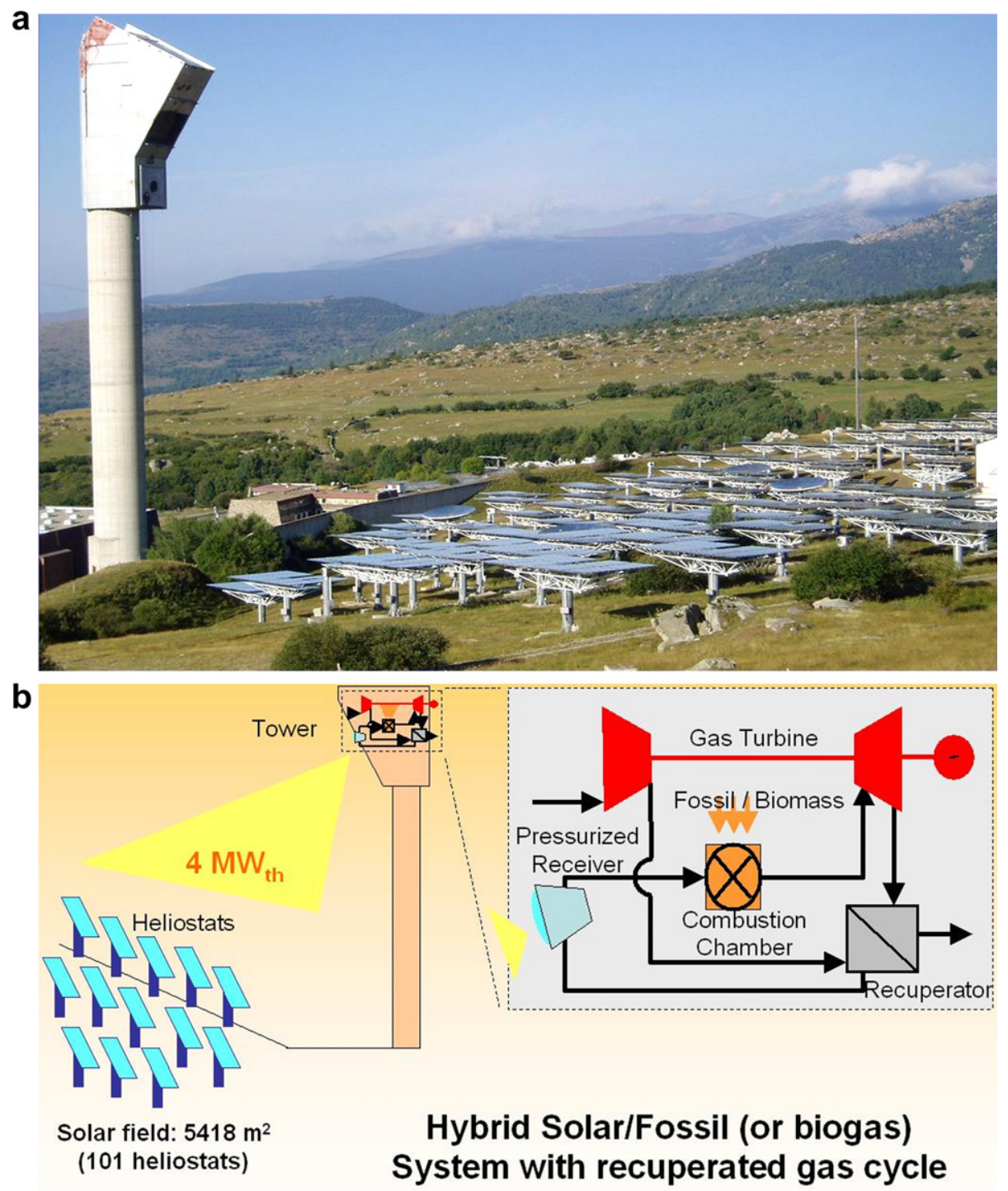

Fig. 1. View of the Themis facility and scheme of the Pegase system.

maps on receiver aperture, to establish efficiency matrixes of the solar field, to optimize the field layout on costs criteria (cost of produced kilowatt-hour, cost of installed kilowatt), and to calculate instantaneous or annual performances of the concentrating system.

Furthermore, an optional feature is to include receiver and thermal cycle models to simulate the whole installation and to analyze its performances, as two of the screened codes do. This global simulation on an annual basis can also be done by integrating the heliostat field and tower subsystem in less specific tools, such as TRNSYS (Schwarzbözl et al., 2002), SOLERGY (Stoddard et al., 1987), or ECOSTAR (Pitz-Paal et al., 2005). The simplified model developed for the ECOSTAR program combines steady-state component efficiencies from experimental or simulated curves. This method is relevant to assess an annual production, but not to simulate the operation of a whole installation on shorter periods when the system dynamics should be considered. TRNSYS may be adapted to model transient behavior of CSP systems, during startup, shut-down or variable weather periods. However this third kind of problem, very useful to define operation strategies of a CRS, is not tackled in this paper.

\section{Abbreviations and glossary}

- Abbreviations: In this document the following definitions are used:

\begin{tabular}{|c|c|c|c|}
\hline CRS & $\begin{array}{l}\text { Central receiver } \\
\text { system }\end{array}$ & HSGT & $\begin{array}{l}\text { Hybrid solar and } \\
\text { gas turbine }\end{array}$ \\
\hline CSP & $\begin{array}{l}\text { Concentrating solar } \\
\text { thermal power }\end{array}$ & PT & Parabolic trough \\
\hline DS & Dish-stirling & PV & Photovoltaic \\
\hline
\end{tabular}

- Solar field efficiency: reflected power arriving on the receiver aperture divided by the product of the incident 
solar power by the total area of mirrors. It includes reflectivity of the mirrors, cosine factor due to the incident angle of the sun on the heliostats, atmospheric attenuation between the heliostats and the receiver, shadowing and blocking effects, and spillage of the flux around the receiver aperture. For the mean annual efficiency, heliostat availability is also taken into account.

- Shadowing and blocking effects (S\&B): a shadow is a mask (neighboring heliostat, tower) in the incident ray path between the sun and the heliostat surface; a block is a mask (neighboring heliostat) in the reflected ray path between the heliostat surface and the receiver.

- Solar field efficiency matrix: bi-dimensional matrix giving the solar field efficiency as a function of sun position (azimuth and elevation). Integrated in tools for performance analysis of CSP systems, such a matrix makes it possible to assess the solar field efficiency all year long. Generally speaking, reflectivity of the mirrors is not included because it may vary during a year.

\section{Some principles of heliostat field modeling}

The optical components of a CRS are designed to form an image of the solar disk on a focal plane. However the obtained solar spot has neither the same size nor the same luminance as the sun, because of the following phenomena (Hénault, 1987):

\section{- sun and collector geometry}

- size and luminance of the sun, varying every day by diffusion in the atmosphere,

- optical aberrations, like heliostat astigmatism, caused by the design of the reflective surfaces,

- specific defects of solar facilities

- microscopic errors of reflective facets, often considered as negligible,

- pointing (or tracking) errors, well known,

- curvature and canting errors of facets or modules.

To calculate concentrated solar irradiance, usual approaches are ray-tracing and convolution methods. The principle of ray-tracing methods (or statistical or Monte Carlo methods) is to choose randomly a bundle of rays coming from a surface 1 , and then to determine which of them arrive on a surface 2 . The irradiance of an elementary surface is proportional to the number of impacting rays (Matteï, 2005). In the case of a concentrator with one reflection, this algorithm is used twice, first between the sun and the reflective surface with an energetic distribution corresponding to the sun shape, then between the heliostat facet and the receiver with a statistic law for the error distribution related to the defects of the facet. Precision and calculating time increase with the number of rays and the complexity of geometry. In convolution methods (or cone optics), reflected rays from elementary mirrors are considered with error cones calculated by convolutions of normal Gaussian distributions corresponding to each error (sun shape and heliostat errors).

A systematic comparison shows that with the same hypothesis similar results can be reproduced with ray-tracing and convolution methods (Pitz-Paal and Schwarzbözl, 2000). Simulation errors often come from an incomplete description of reflective surfaces and sun shape properties. Nevertheless ray-tracing methods are more flexible and are able to model non-ideal optics (non-imaging concentrators). Indeed they have the advantage of reproducing real interactions between photons and therefore of giving accurate results for small or complex systems but they need higher calculating time and computing power. That is why it is not recommended to use ray-tracing techniques for system optimization.

About the accuracy of codes using convolution/expansion techniques (Walzel et al., 1977) found peak flux error and average absolute error in the range of $1-2 \%$. This is comparable to what can be obtained from a ray-tracing codes like SOLTRACE. Kistler (1986) states that annual performances of a solar field can be deduced with accuracies better than $1 \%$. Comparison between first generation codes on a small field (CESA-1) shows very good agreement (about 1\% deviation for the power on receiver, $3 \%$ for the peak flux). However the accuracy to predict flux and spillages decreases when the slant range decreases with respect to heliostat and receiver size and in particular with high precision heliostat (low canting, focusing and pointing errors). Nevertheless one have to keep in mind that the greatest errors observed on annual performance of a CRS do not come from the optical model but from the other components model (turbine, storage...).

\section{First generation codes}

First codes designed to calculate solar flux concentration in a CRS came from preliminary studies carried out in the US for Solar One in the late 70s. Among them one may quote HELIOS, MIRVAL and DELSOL, which are still used today. HELIOS was initially developed for analyzing experiments at Sandia's CRTF (Biggs and Vittitoe, 1977). This code can be adapted to all kind of small-sized plants and has become a widespread tool for facility comparison used by many research teams. It can model not only CRS but has also been modified to analyze the optical performances of parabolic troughs (DLR version) or even dishes. This FORTRAN code is based on a cone optics approach: flux density is produced combining error cone of the reflected ray and sun shape by convolution of independent distributions with Fourier transform. Heliostat facets of any shape and any curvature are divided into small elementary mirrors reflecting the sun image on the receiver aperture. HELIOS is considered by Izygon et al. (1987) to be the most flexible and sensitive code of its generation because of its low calculation time and its accuracy. However this tool needs a detailed description of heliostats geometry, it is quite complex and hard to use for an inex- 
perienced user (Izygon et al., 1987). It is not adapted to large heliostat fields, it can neither assess annual performances, nor optimize heliostat layout, nor use secondary optics. That is why we decided not to include HELIOS in our comparative study, contrary to MIRVAL and DELSOL.

Simultaneously in France numerous codes were developed before and during experiments at Themis. These are accurate and agree well with US codes from the same period (Izygon et al., 1987), but they are not dedicated to forecast performances of other CRS facilities (Hénault, 1987). Moreover when they were written computing techniques and hardware highly differ from current ones, and they have not been updated since the $80 \mathrm{~s}$. On a theoretical point of view, advanced mathematical models were used, but none of these tools has a user-friendly interface. The only code that has evolved after the Themis experiment is now called COSAC (Hénault, 2005). This is a ray-tracing calculation tool without approximation, adapted to complex optical systems (spatial optical devices, 3-D spectrometers) but not to heliostat field modeling. Actually the user would need to describe heliostats one by one, to calculate sun position, to add instructions to account for shadowing and blocking. At the time of Themis, flux measurements techniques were still lacking precision, so comparisons between measures and calculations made illusive any improvement in accuracy of simulation codes (Izygon et al., 1987).

\section{Currently used codes}

To compare in an objective and reliable way the features of tools currently used in research centers working on CSP technologies, a questionnaire was sent to developers or heavy users of six codes (UHC, DELSOL, HFLCAL, MIRVAL, FIAT LUX and SOLTRACE). This inquiry contained 23 questions about physical and computational model used, user interface developed, parameters involved, and results obtained.

\subsection{Results of the inquiry}

Table 1 sums up the main characteristics of these codes.

These tools have features in common. First all of them use exact physical considerations to calculate cosine factor and $\mathrm{S} \& \mathrm{~B}$, except FIATLUX for which this feature is not implemented yet. Likewise all codes can be run in Windows environment on standard computers with user-friendly graphic interfaces like flux maps and 3-D visualization of the installation (Fig. 2) except for MIRVAL. The size of the solar field is not limited. These tools are in the public domain, except FIAT LUX which availability is pending on CIEMAT decision according to software policy, and HFLCAL. However source codes of SOLTRACE and some additional programs (WINDELSOL interface by CIEMAT or DLR extensions for MIRVAL) are not available now.

\subsection{Two categories of codes}

As it can be observed in Table 2, two main categories can be distinguished.

These two categories show many differences because they do not have the same objectives. MIRVAL, FIATLUX and SOLTRACE give a detailed description of the reflected power from a heliostat field but include neither thermodynamic conversion nor heliostat field optimization contrary to UHC, DELSOL and HFLCAL. These latter codes contain more approximations in their resolution methods, so they can quickly assess the annual performances of a large-size heliostat field but give less accurate results for small solar fields. To sum up, MIRVAL, FIATLUX, SOLTRACE or even HELIOS model the heliostat field and tower subsystem whereas UHC includes the receiver, and DELSOL, and HFLCAL simulate the whole CRS including receiver and power block.

\subsection{Main features of each code}

\subsubsection{University of Houston codes}

UHC codes (sometimes called RCELL suite) are a suite of interconnected Fortran 77 codes, each with a number of optional operating modes, dealing primarily with the optical design of heliostat fields and receivers. Thermal and economic algorithms are incorporated to enable optimization, performance and design studies of the complete plant. Three of these codes are dedicated to the optical subsystem (Falcone, 1986):

- NS (cellwise performance) provides interception and flux data, diurnal and annual flux data for fixed designs. The solar field is divided into cells corresponding to regions with uniform heliostat density or fixed number of heliostats, or single heliostats and performance is calculated for a representative heliostat in each cell (Lipps and Vant-Hull, 1978),

- RCELL (cellwise optimization) optimizes solar components (heliostat spacings in field, field boundaries, tower and receiver dimensions) on cost/performance criteria obtaining interception factors for the optimization from a very simple model (for initial trials) or for accurate results from NS outputs ("node files"),

- IH (individual heliostat layout and performance code) is a detailed layout processor using RCELL data to specify each heliostat location and can also compute performance for each heliostat or for the whole field.

Input is contained in four modules defining the site and weather, the heliostat design, the receiver design, and the type of run (interception data, field optimization, system optimization, heliostat layout or annual performance). By generating and using data bases ("cosine, shading, and blocking files" and "node files") computing time is saved (Falcone, 1986). UHC codes have been used to optimize 
Table 1

Main features of five codes for concentrated solar flux calculation

\begin{tabular}{|c|c|c|c|c|c|c|}
\hline Name of code & $\mathrm{UHC}$ & DELSOL & HFLCAL & MIRVAL & FIAT LUX & SolTRACE \\
\hline References & $\begin{array}{l}\text { Pitman and Vant-Hull, } 1989 \\
\text { Laurence et al., } 1984 \text { Lipps } \\
\text { and Vant-Hull, 1980a,b }\end{array}$ & Kistler, 1986 & Kiera, 1986 & $\begin{array}{l}\text { Leary and } \\
\text { Hankins, } \\
1979\end{array}$ & Monterreal, 2000 & $\begin{array}{l}\text { Wendelin, } \\
2003\end{array}$ \\
\hline $\begin{array}{l}\text { Research } \\
\text { team }\end{array}$ & University of Houston & SANDIA & GAST project & SANDIA & CIEMAT-PSA & NREL \\
\hline $\begin{array}{l}\text { Currently } \\
\text { used by }\end{array}$ & SANDIA, Tietronix & CIEMAT, SANDIA & DLR & $\begin{array}{l}\text { DLR, } \\
\text { SANDIA }\end{array}$ & CIEMAT & $\begin{array}{l}\text { NREL, } \\
\text { CNRS }\end{array}$ \\
\hline $\begin{array}{l}\text { Considered } \\
\text { technologies }\end{array}$ & CRS-SF & CRS & CRS & CRS & CRS & $\begin{array}{l}\text { CRS-PT-DS- } \\
\text { SF }\end{array}$ \\
\hline $\begin{array}{l}\text { Development } \\
\text { start }\end{array}$ & 1974 & 1978 & 1986 & 1978 & 1999 & 1999 \\
\hline Availability & Source and executable version & $\begin{array}{l}\text { Source and executable } \\
\text { version }\end{array}$ & Not available & $\begin{array}{l}\text { Source and } \\
\text { executable } \\
\text { version }\end{array}$ & $?$ & $\begin{array}{l}\text { Executable } \\
\text { version }\end{array}$ \\
\hline $\begin{array}{l}\text { Programming } \\
\text { language }\end{array}$ & FORTRAN/C++ & FORTRAN/Basic & FORTRAN & FORTRAN & MATLAB & Delphi5 \\
\hline $\begin{array}{l}\text { Flux } \\
\quad \text { calculation } \\
\text { method }\end{array}$ & $\begin{array}{l}\text { Hermite polynomial } \\
\text { expansion/convolution }\end{array}$ & $\begin{array}{l}\text { Hermite polynomial } \\
\text { expansion/convolution }\end{array}$ & $\begin{array}{l}\text { Simplified convolution } \\
\text { of each heliostat's flux }\end{array}$ & $\begin{array}{l}\text { Monte } \\
\text { Carlo ray- } \\
\text { tracing }\end{array}$ & $\begin{array}{l}\text { Normally } \\
\text { distributed random } \\
\text { value of 'slope } \\
\text { error' }^{\mathrm{c}}\end{array}$ & $\begin{array}{l}\text { Monte Carlo } \\
\text { ray-tracing }\end{array}$ \\
\hline Receiver type & $\begin{array}{l}\text { Flat, cavity or external } \\
\text { cylinder }\end{array}$ & $\begin{array}{l}\text { Flat, cavity or external } \\
\text { cylinder }\end{array}$ & $\begin{array}{l}\text { Flat, cylindrical or } \\
\text { conical }\end{array}$ & $\begin{array}{l}\text { Flat, cavity } \\
\text { or external } \\
\text { cylinder }\end{array}$ & Flat & $\begin{array}{l}\text { Almost any } \\
\text { receiver } \\
\text { configuration }\end{array}$ \\
\hline $\begin{array}{l}\text { Multiple } \\
\text { reflections }\end{array}$ & $\begin{array}{l}\text { Beam-down but not secondary } \\
\text { concentrators }\end{array}$ & No & Yes & Yes & No & Yes \\
\hline $\begin{array}{l}\text { Contribution } \\
\text { of each loss }\end{array}$ & Yes & Yes & Yes & Yes & No & No \\
\hline $\begin{array}{l}\text { Annual } \\
\text { performances }\end{array}$ & Yes & Yes & Yes & Yes & No & No \\
\hline $\begin{array}{l}\text { Optimized } \\
\text { components }\end{array}$ & $\begin{array}{l}\text { Heliostats layout and } \\
\text { boundary, tower height, } \\
\text { receiver geometry }\end{array}$ & $\begin{array}{l}\text { Heliostat boundary, } \\
\text { layout }^{\mathrm{a}}, \text { tower height, } \\
\text { receiver size, storage } \\
\text { capacity }\end{array}$ & $\begin{array}{l}\text { Heliostat layout, tower } \\
\text { height, receiver area } \\
\text { and orientation }\end{array}$ & $\begin{array}{l}\text { Heliostat } \\
\text { layout }^{\mathrm{b}}\end{array}$ & Not available & $\begin{array}{l}\text { Not } \\
\text { available }\end{array}$ \\
\hline $\begin{array}{l}\text { Optimization } \\
\text { criteria and } \\
\text { constraints }\end{array}$ & $\begin{array}{l}\text { Energy or cost criteria with } \\
\text { allowable flux/land constraint }\end{array}$ & $\begin{array}{l}\text { Cost criteria with optional } \\
\text { flux/land constraints }\end{array}$ & Energy or cost criteria & $\begin{array}{l}\text { Energy } \\
\text { criteria }^{b}\end{array}$ & Not available & $\begin{array}{l}\text { Not } \\
\text { available }\end{array}$ \\
\hline
\end{tabular}

${ }^{a}$ Uses UHC defined spacings.

b With DLR additional program only.

${ }^{c}$ For each unitary normal vector to the mirror surface, then calculation of deterministic trajectories for the bundle of reflected rays coming from solar disk with geometric optics laws.

heliostat fields and to evaluate optical performance of a number of CRS, including solar one and solar two.

Interesting features were added during solar two design and operation: an allowable flux constraint was used to optimize the new heliostat layout (Vant-Hull and Pitman, 1988) and a C++ version of UHC incorporating the structure and imaging characteristics of $\mathrm{IH}$ helped to compute, in real-time, aiming strategies to control solar flux density on a receiver aperture (protection against excess flux density) (Vant-Hull et al., 1996a).

\subsubsection{DELSOL/WINDELSOL}

This FORTRAN code was developed to fill the need for an accurate, yet fast, easy to use tool for performance analysis, design and optimization of large and small power systems for electricity and process heat applications (Kistler, 1986). It typically requires less computer time for perfor- mance calculations than either MIRVAL or HELIOS (Falcone, 1986). DELSOL is based in part on the performances design approaches developed at the University of Houston (images generated by Hermite polynomials convolution, solar field divided into zones defined by their heliostat density for optimization). DELSOL optimizes tower height, receiver dimensions, and field boundaries on an economic basis, but requires a definition of the heliostat spacings in the field.

WINDELSOL is an adaptation of DELSOL for Windows with new features (user-friendly interface, optimized defined-by-coordinates heliostat field generation...) but cannot be used to analyze existing facilities (heliostat coordinates cannot be user-defined). Subdivision of field into sectors and data entry organization make it difficult to introduce new optical parameters. This program seems to be adapted to large systems but, as its developers grant, 


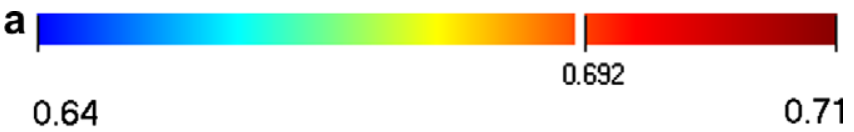

0.64

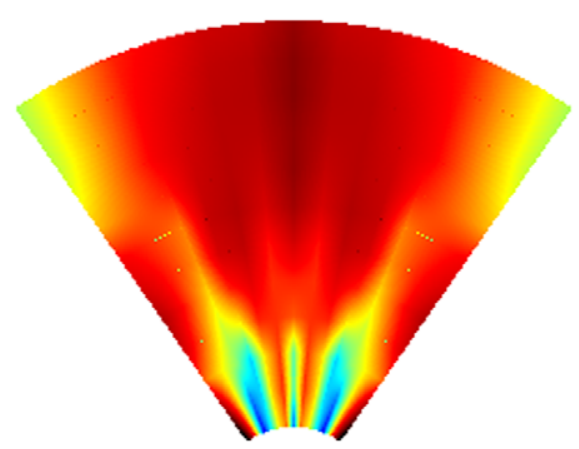

b

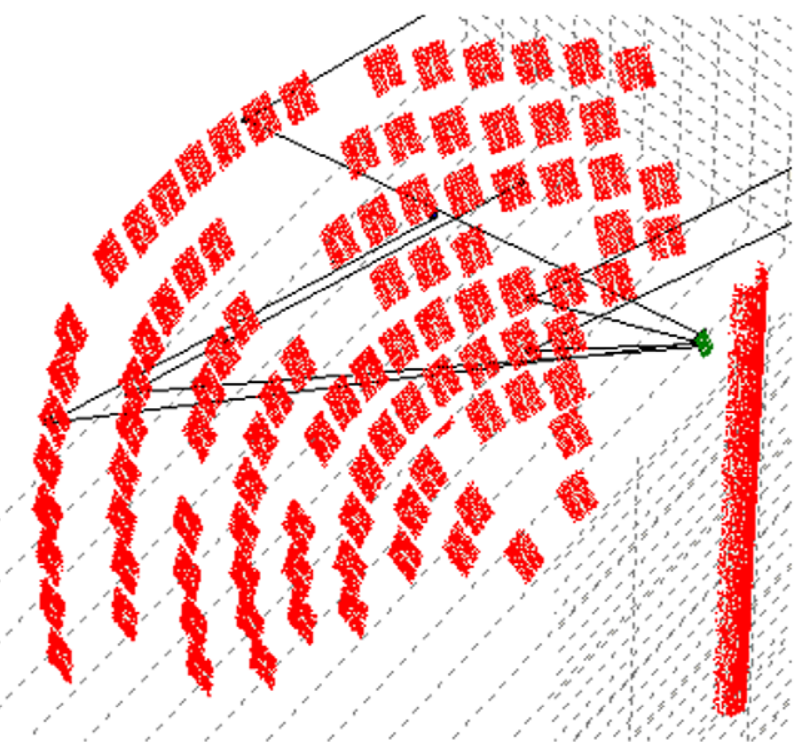

Fig. 2. Visualization of results from Windelsol and Soltrace for the Pegase facility: (a) annual performances of the solar field from WINDELSOL (view from above); (b) impacting rays on the collector surface from SOLTRACE.

not accurate for small plants. Its user-friendliness turns it to an interesting tool for preliminary studies of large CRS projects.

\subsubsection{HFLCAL}

HFLCAL code (for "Heliostats Field Layout CALculations") was developed for the GAST hybrid concept
(1986), and then applied to other concepts (like Phoebus). It calculates the annual production of a CRS plant depending on its configuration (heliostats, tower, receiver, cycle). The layout and optimization of the global system are designed to maximize electricity production per heliostat or minimize the cost of produced electricity. The annual production is assessed with an error smaller than $5 \%$ in comparison with the US codes HELIOS, DELSOL, and UHC (Kiera, 1989). Nowadays it is still updated and used for CRS modeling by DLR researchers (Final Technical Report Solgate, 2005), who consider it easier to adapt than DELSOL.

HFLCAL is able to carry out the hundreds of annual performance calculations needed for determining a costoptimized solar field layout in a reasonable time. It uses a simplified optical model with a flux distribution reflected by each heliostat approached by a circular Gaussian distribution obtained by convolution of three distributions (one accounting for the size and the luminance of the sun, a second for the heliostat error and a third one for tracking errors). Conversely in the 4 other codes described here various mirror errors are detailed (curvature, canting, microscopic...) panel by panel. Thus in HFLCAL it is sufficient to consider the central ray of one heliostat and to include these three errors with three standard deviations, according to a model settled by Rabl (1985). Consequently this code only does one calculation per heliostat whose focal length is considered constant or equal to slant range.

HFLCAL was used during the SOLGATE project to cost-optimize the solar part of a hybrid CRS plant with pressurized air volumetric receiver. Heliostat field size and layout, tower height, receiver geometry were adapted to the specific needs of HSGT systems for a given capacity at a given location. Comparisons with experimental measures showed that total power on receiver aperture can easily be calculated with high precision, whereas the precision on maximum flux is low and the flux distribution is not accurate (Final Technical Report Solgate, 2005).

\subsubsection{MIRVAL}

This tool was developed for the rigorous optical performance analysis of the envisaged concepts during Solar One preliminary study. It was used to check flux calculations from DELSOL, HELIOS and UHC. It is quite simple to

Table 2

Two categories of flux calculation codes

\begin{tabular}{|c|c|c|}
\hline & Optimization codes & Performance analysis codes \\
\hline Tools & UHC-RCELL, (WIN)DELSOL, HFLCAL & $\begin{array}{l}\text { UHC-IH or NS, MIRVAL, FIAT LUX, } \\
\text { SOLTRACE, HELIOS, (DELSOL) }\end{array}$ \\
\hline Considered subsystems & Overall plant & Optical subsystem \\
\hline Data entry & $\begin{array}{l}\text { Total ground area of the solar field divided } \\
\text { into zones, in windows }\end{array}$ & Detailed heliostat geometry, in text files. \\
\hline Calculation method & Simplified convolution & Monte Carlo or similar \\
\hline Calculation time & Some seconds for a whole heliostat field & Some seconds to some minutes for one single heliostat \\
\hline Accuracy & Increase with field size & Accurate for one heliostat \\
\hline Economic calculations & Yes & No \\
\hline
\end{tabular}


use and, as it is implemented with Monte Carlo method, ray vectors onto the receiver aperture can be provided, so as to interface with a receiver or secondary concentrator model. For Izygon et al. (1987), MIRVAL turned out to be unsuitable for modeling the complex geometry of CETHEL heliostats of the Themis field.

\subsubsection{FIAT LUX}

Initially designed to validate the optical quality of heliostats, it enables the user to analyze in details existing installations, with a sharp representation of the heliostat geometry. Heliostat orientation can be easily checked before calculation by $3-\mathrm{D}$ visualization of reflected rays from the center of the facets. Flux distribution after calculation is statistically described. FIAT LUX was compared with HELIOS on a Martin-Marietta heliostat, showing good agreement (Monterreal, 2000). Nevertheless this tool is now being developed: a few functionalities are still missing such as S\&B effects and user interface.

\subsubsection{SOLTRACE}

The objective of SOLTRACE is to model complex optical systems for solar power and to analyze their performance (Wendelin, 2003). It is adapted not only to the three main technologies to thermodynamically convert sun power into electricity (CRS, PT and DS) but also to solar furnaces. The optical system is organized in stages in a global coordinates system: stages are sections of the optical geometry that are successively hit by rays in their pathway from the sun to the final receiver. They can be optical ones (physical interactions with rays) or virtual ones (useful to determine positions of rays or flux maps wherever in the system without interacting with them). The reason for this organization is to trace rays in an efficient way in order to limit calculation time. One stage is composed by elements with their own aperture, shape, and optical properties (slope error, specularity error, reflectivity, transmissivity, and refraction). Each element is described in a coordinates system related to its stage.

Contrary to other tools, atmospheric attenuation and tracking errors are not directly included but they can be taken into account, respectively, in the reflectivity of the mirrors and in their slope error. Moreover the complete description of geometry of the elements leads to a cumbersome interface. Indeed for each system all the heliostat field geometry must be built in a spreadsheet including:

- definition of the center, the aperture, the normal direction, and the curvature of each facet of each heliostat in the stage coordinates system;

- definition of each stage coordinates system in relation to the global coordinates system.

This organization implies the calculation of the position of each facet of each heliostat depending on the sun position.

\section{Other codes}

The ray-tracing code OPTEC (for "optimization program for terminal concentrators", Schoffel and Sizmann, 1991) can handle a solar furnace (Neumann and Witzke, 1999), a heliostat field or a parabolic dish and add a cone, trumpet or compound parabolic concentrator as terminal concentrator.

Similarly to research centers, industrial groups promoting CSP projects took an interest in calculation of solar field performances through the development of similar tools, often dedicated to design optimization, and not diffused. For example one can note SOLVER from SOLUCAR (ray tracing for CRS modeling) and SENSOL from SENER (for CRS and PT modeling, Relloso and Domingo, 2006).

To complete this overview we shall also quote codes currently in development, intended to replace codes from the 80 s, sometimes considered as hard to use and modify, non-adapted to dynamic modeling, lacking documentation, and limited by obsolete computing power constraints (Blanco et al., 2005). These new codes, more modular, will tackle more easily simulation of new CSP systems, such as hybrid concepts, cogeneration plants or with multi-staged receivers. Besides SOLTRACE which may constitute the first code of this generation, TONATIUH (Blanco et al., 2005) aims to be a sophisticated software environment for design, optimization and analysis of all CRS, PT, and DS. This open source ray-tracing code will enable users to visualize the installation with state-of-the-art 3-D interface technologies. CIEMAT laboratory is currently developing a series of tools called SCT (Solar Concentration Toolbox) Package, developed under MATLAB software (Sanchez and Romero, 2006). One tool is dedicated to optical design and optimization of solar receivers, another one to generation of random rays, and the last one to CRS optimization and performance. These codes will use either ray-tracing or convolution techniques. At last the EPFLLENI laboratory worked to integrate a heliostat-tower model built with RADIANCE in a MATLAB environment and has recently developed a multi-objective evolutionary algorithm for the design of heliostat fields (Pelet et al., 2006).

\section{How to chose an adapted calculation code?}

For researchers or engineers that would need to model CRS, it may be difficult to find the right tool that best fit to the question asked. We hope that this study will help them to solve this problem. In the case of an industrial project, an interesting strategy may be to determine first the general layout of the plant (tower height, heliostat field boundary, receiver geometry and technology, storage capacity) from key parameters such as power block characteristics, meteorological data, and load curves. This analysis can be done with tools from the first category. Then a 
more detailed study including a closer description of heliostats and receiver geometry can be led with tools from the second category to assess solar field performances or to improve pointing and operating strategies.

Another approach to assess global performances of CRS may be the following:

- first to use solar field efficiency matrixes and receiver performances curves from specific codes like the five ones quoted above,

- then to integrate these data in TRNSYS with STEC library or in less detailed tools based on a simple energy balance formulation (SOLERGY, ECOSTAR).

With this second approach, one component can be modified more easily without changing the global model. Besides a wider range of concepts can be simulated. However efforts must be made to link components in a consistent way to avoid discrepancies.

\section{Conclusions and perspectives}

This study has permitted us to classify tools into two categories, corresponding to two types of problems encountered in studies on CSP technologies:

(1) optimization codes to design installation projects like HFLCAL, UHC-RCELL, or (WIN)DELSOL;

(2) performance analysis codes to assess optical performances of a given installation like FIAT LUX, MIRVAL, UHC-NS or IH, or SOLTRACE.

It is worth noting that other types of modeling tools might be necessary to design and study CRS systems like specific codes for receiver modeling, for heliostat field layout optimization or transient analysis.

For research laboratories or industrial developers, it seems interesting to use one code from each category. Indeed codes from the first category are able to assess the available flux distribution at the top of a tower and thus to size up a receiver. That is why we chose to use SOLTRACE to model the optical components of an existing facility. This code will be used to study the solar field performances depending on pointing strategy, to describe the flux distribution on receiver module aperture, and to elaborate an accurate efficiency matrix. Besides SOLTRACE can be adapted to other concentrating systems (solar furnaces, dish-Stirling). Tools from the second category, like (WIN)DELSOL, are recommended for techno-economic assessment of CRS technologies. However various additions or modifications must be brought to adapt them to new CRS concepts.

Comparing results of updated codes from both categories on one or various reference test cases should be a challenging work in partnership for research centers involved in CRS or other CSP technologies.

\section{Acknowledgements}

The authors wish to thank Allan Lewandowski from NREL, Marcelino Sanchez and Rafael Monterreal from CIEMAT, Mark Schmitz, Peter Schwarzbözl, and Reiner Buck from DLR, François Hénault from CRAL - Observatoire de Lyon, Manuel Blanco from University of Texas, Lorin Vant-Hull from University of Houston and Rafaele Bolliger from EPFL-LENI for their invaluable help.

\section{References}

Biggs, F., Vittitoe, C.N., 1977. HELIOS: a computational model for solar concentrators, Sandia National Labs, Albuquerque, NM, US-USSR Workshop on Solar Energy Appl., Moscow.

Blanco, M.J., Amieva, J.M., Mancilla, A., 2005. The TONATIUH software development project: an open source approach to the simulation of solar concentrating systems. In: Proceedings of 2005 ASME International Mechanical Engineering Congress and Exposition, Orlando, Florida.

Falcone, P.K., 1986. A Handbook for Solar Central Receiver Design, Sandia Report SAND86-8009.

Final Publishable Report Solgate, solar hybrid gas turbine electric power system, 2005. Contract ENK5-CT-2000-00333, Project Partly Funded by the European Community in the Framework of the 5th RTD Framework Programme 1998-2002. Partners: Ormat, Ciemat, DLR, Solucar, Tuma, http://ec.europa.eu/research/energy/pdf/solgate_en. pdf.

Garcia, P., Ferriere, A., Flamant, G., Costerg, P., Soler, R., Gagnepain, B., 2006. The PEGASE project: design and performance evaluation of a hybrid solar/fossil gas turbine system for electricity generation. In: Romero, M., Martínez, D., Ruíz, V., Silva, M., Brown, M. (Eds.), Proceedings of SolarPACES 13th International Symposium on Concentrated Solar Power and Chemical Energy Technologies, June 20 23, Seville, Spain, pp. A5-S6.

Hénault, F., 1987. Concentration du rayonnement solaire par simple et double réflexion: contribution aux méthodes de réglage et de contrôle des surfaces réflectrices à facettes, thèse soutenue à l'Université de Paris-Sud, pp. 35-60.

Hénault, F., 2005. COSAC Version 2.5, Présentation Générale, http:// francois.henault.free.fr/cosac/cosac252_1.pdf.

Izygon, M., Bezian, J.J., Hénault, F., 1987. Modélisation des flux réfléchis par un champ d'héliostats, Comparaison de divers modèles. Proceedings of Séminaire héliothermie. Springer, NY.

Kiera, M., 1986. Beschreibung und Handhabung des Programmsystems HFLCAL, Interatom Report.

Kiera, M., 1989. Heliostat field: computer codes, requirements, comparison of methods. In: Becker, M., Böhmer, M. (Eds.), Proceedings of the Final GAST Presentation. Springer, Lahnstein, Germany, pp. 95 113.

Kistler, B.L., 1986. A user's manual for DELSOL3: a computer code for calculating the optical performance and optimal system design for solar thermal central receiver plants, Sandia Report SAND86-8018.

Laurence, C.L., Lipps, F.W., Vant-Hull, L.L., 1984. User's manual for the University of Houston individual heliostat layout and performance code. Houston University, TX.

Leary, P.L.; Hankins, J.D., 1979. Users guide for MIRVAL: a computer code for comparing designs of heliostat-receiver optics for central receiver solar power plants, Sandia Report SAND-77-8280.

Lipps, F.W., Vant-Hull, L.L., 1978. A Cellwise method for the optimization of large central receiver systems. Sol. Energ 20, 505-516.

Lipps, F.W., Vant-Hull, L.L., 1980a. Programmer's manual for the University of Houston computer code RCELL: cellwise optimization for the solar central receiver project, Technical Report Number(s) DOE/SF/10763-T5, SAND-0763-1. 
Lipps, F.W., Vant-Hull, L.L., 1980b. In: User manual for the University of Houston solar central receiver, cellwise performance model: NS, vol. 1. Houston University, TX.

Matteï, S. 2005. Rayonnement thermique des matériaux opaques, Techniques de l'ingénieur, file BE8210.

Monterreal, R., 2000. Software developments for system analysis and optimization. SolarPACES Tech. Report No. III-3/00. In: Pitz-Paal, R., Schwarzbözl, P. (Eds.), Proc. of the IEA SolarPACES Task III Workshop on Simulation of Solar Thermal Power Systems 2000, Cologne, Germany.

Neumann, A., Witzke, A., 1999. The influence of sunshape on the DLR solar furnace beam. Sol. Energy 66, 447-457.

Pelet, X., Favrat, D., Sanchez, M., Romero, M., 2006. Design of heliostat fields using a multi-objective evolutionary algorithm. In: Romero, M., Martínez, D., Ruíz, V., Silva, M., Brown, M. (Eds.), Proceedings of SolarPACES 13th International Symposium on Concentrated Solar Power and Chemical Energy Technologies, June 20-23, Seville, Spain, pp. A7-S1.

Pitman, C.L., Vant-Hull, L.L., 1989. The University of Houston solar central receiver code system: concepts, updates and start-up kits, SAND88-7029, Houston TX, University of Houston.

Pitz-Paal, R., Schwarzbözl, P. 2000. Software developments for system analysis and optimization. SolarPACES Tech. Report No. III-3/00. In: Proceedings of the IEA SolarPACES Task III Workshop on Simulation of Solar Thermal Power Systems, Cologne, Germany.

Pitz-Paal R., Dersch, J., Milow, B., Ferriere, A., Romero, M., Tellez, F., Steinfeld, A., Langnickel, U., Shpilrain, E., Popel, O., Epstein, M., Karni, J., 2005. ECOSTAR Road Map Document, SES-CT-2003502578, ftp://ftp.dlr.de/ecostar/.

Rabl, A., 1985. Active Solar Concentrators and Their Applications. Oxford University Press, New York.

Relloso, S., Domingo, M., 2006. Solar projects analysis using SENSOL. In: Romero, M., Martínez, D., Ruíz, V., Silva, M., Brown, M. (Eds.), Proceedings of SolarPACES 13th International Symposium on Con- centrated Solar Power and Chemical Energy Technologies, June 2023, Seville, Spain, pp. A7-S8.

Sanchez, M., Romero, M., 2006. Methodology for generation of heliostat field layout in central receiver systems based on yearly normalized energy surfaces. Solar Energy 80, 861-874.

Schoffel, U., Sizmann, R., 1991. Final report terminal concentrators. Solar Thermal Energy Utilization. Springer, Berlin, p. 183, 3-53268-4.

Schwarzbözl, P., Eiden, U., Pitz-Paal, R., 2002. A TRNSYS model library for solar thermal electric components (STEC), a reference manual release 2.2. IEA-solar power and chemical energy systems, Task III: solar technologies and applications, http://sel.me.wisc.edu/trnsys/trn$\mathrm{lib} / \mathrm{stec} / \mathrm{stec} 2.2$ refguide.pdf.

Stoddard, M.C., Faas, S.E., Chiang, C.J., Dirks, A.J., 1987. SOLERGY A Computer Code for Calculating the Annual Energy from Central Receiver Power Plants. SAND86-8060. Sandia National Laboratories, Livermore, $\mathrm{CA}$.

Vant-Hull, L.L., Pitman, C.L., 1988. Central receiver system optimization under an allowable flux constraint. In: Gupta, B.P., Traugott, W.H. (Eds.), Proceedings 4th International Symposium on Solar Thermal Technology-Research, Development and Applications, Santa Fe, NM. Hemisphere Publishing Corporation, New York, pp. 51-60.

Vant-Hull, L.L., Izygon, M.E., Pitman, C.L., 1996a. Real time computation and control of solar flux density on a central receiver (solar two ) (protection against excess flux density). In: Campbell-Howe, R., Wilkins-Crowder, B. (Eds.), Proceedings of the ASES Annual Conference. Asheville, NC.

Walzel, M.D., Lipps, F.W., Vant-Hull, L.L., 1977. A solar flux density calculation for a solar tower concentrator using a two-dimensional hermite function expansion. Solar Energy 19 (3), 239-253.

Wendelin, T., 2003. SolTRACE: a new optical modeling tool for concentrating solar optics. In: Proceedings of the ISEC 2003: International Solar Energy Conference, 15-18 March 2003, Kohala Coast, Hawaii, New York, American Society of Mechanical Engineers, pp. 253-260. 